\title{
Impacts of the Problem-based Learning Pedagogy on English Learners' Reading Comprehension, Strategy Use, and Active Learning Attitudes
}

\author{
Lu-Fang Lin \\ Correspondence: Lu-Fang Lin, Institute of Applied English, National Taiwan Ocean University, Taiwan, R. O. C.
}

Received: April 5, 2017

doi:10.11114/jets.v5i6.2320
Accepted: April 26, $2017 \quad$ Online Published: May 7, 2017

URL: https://doi.org/10.11114/jets.v5i6.2320

\begin{abstract}
This study investigated whether an English reading course integrated with the problem-based learning approach could foster foreign language learners' reading comprehension ability, strategy use, and their active learning attitudes. The pedagogy was featured with the small group scaffolding. Two intact English classes in a Taiwanese university were randomly assigned to the experimental and control treatment conditions. The experimental group received problem-based learning instruction, whereas the control group did not. The reading comprehension pre- and post-tests and the English active learning questionnaire were employed to collect the data. The Independent Samples $t$ test yielded a significant difference between the 2 groups in the total score of the reading comprehension post-test, indicating that the PBL approach significantly improved the participants' reading comprehension ability, and the PBL participants' strategy use for identifying the subject matter and supportive details was better than that of their counterparts. The $t$-test results of the questionnaire showed that the PBL participants exhibited a significantly higher degree of active English learning attitude than the non-PBL participants in terms of motivation intensity and desire to learn English. There was a significantly positive correlation between reading comprehension ability and English learning attitude. Finally, instructional recommendations are presented.
\end{abstract}

Keywords: English reading comprehension, learning attitudes, pedagogy, problem-based learning, strategy use

\section{Introduction}

English reading is one of the most fundamental language skills in universities where English is learned as a foreign language (EFL). In most situations, English written text (text books, journals and articles, online resources, and texts translated from other foreign languages, etc.) is a major medium for delivering worldwide and cutting-edge knowledge. University students need to rely on their English reading skills to advance their professional knowledge both in and out of the classroom. In order to educate and train the students English reading skills, the instructors may need to teach more than just the skill itself.

In addition to cultivating students' reading skills to comprehend course content, the instructor needs to foster the students' positive reading attitudes. Lipson and Wixson (1992) indicated that students' attitudes are a crucial factor influencing their reading comprehension (RC). Advocating multimedia learning, Mayer (2005) also claimed that the instructional effects can be optimal when learners are active and motivated. Active learning is the starting point of a perpetual learning cycle in which EFL learners begin to cultivate sustainable reading habits, master English reading skills, and eventually enjoy reading.

An active attitude is indispensable to English learning because it may direct the learners' efforts toward learning English effectively, and it may even decide the successfulness of their English learning. With experience of teaching English in Taiwan, Lin (2016, pp. 53-54) pointed out some of the limiting conditions in EFL classrooms: (1) the EFL context entails limited resources for authentic immersion in a comprehensive English-speaking environment, (2) most of the teachers in all levels of schools are not native English speakers; Mandarin is the primary language used as the medium of instruction in English courses in most primary and secondary schools, and (3) most students learn English as a subject to pass entrance examinations to enter secondary school and tertiary level educational institutes, and thus their learning goal is test-oriented. Regarding the tertiary level of education in Taiwan, there is limited time for university students to learn English in class. With these limited conditions, it is pertinent for the teacher to foster students' active learning attitudes and extend their learning out of class.

In this study, I intended to adapt an English reading curriculum so that the students' English linguistic knowledge, the 
content of the articles, as well as the learners' attitudes could be addressed adequately. In response to the educational sustainability objective, the problem-based learning (PBL) approach was integrated into an English reading curriculum to extend students' reading outside the classroom. The PBL approach is an educational approach, originally developed in medical schools in the 1960s in Canada, which has served as a framework of instructional design principles, the implementation of which has expanded to numerous other education fields (Barrows, 2000; Boud \& Feletti, 1991; Savery, 2006; Shin \& Kim, 2013). The education areas, for example, include architecture, business and management, engineering, law, nursing, physics, and science. Due to the above mentioned limited conditions in the EFL context, the PBL pedagogy in the present study focuses on small-group scaffolding. A small-group interaction framework in a PBL curriculum is therefore presented.

Regarding second and foreign language education, Azman and Shin (2012) conducted a survey investigating the students' perceptions of PBL in Malaysia and indicated that little research has been conducted to examine the effectiveness of PBL in the context of learning English as a second language. Empirical studies conducted in EFL contexts are also limited in number. Beginning with the intention to provide evidence in another EFL context, Lin (2017b) integrated the PBL pedagogy into a web-based English reading course in a university in Taiwan in which the PBL participants achieved significant achievements in English reading comprehension. To further extend the PBL research in English education, I then investigated the impacts of PBL on EFL learners' RC strategy use and their English learning attitudes in detail. The current study also explored whether there was a significant relationship between the students' RC ability and English learning attitudes. The contribution of the present study is that the English reading curriculum not only put emphasis on how to learn English linguistic knowledge, but also focused on the development of the learners' strategy usage and active English learning attitudes (AELAs).

\section{Literature Review}

\subsection{Theoretical Backgrounds of Small Group Scaffolding in the Problem-based Learning Approach}

The Problem-based learning (PBL) approach features a learner-centered, problem-based, and small-group pedagogy. The educational significance is that PBL "empowers learners to conduct research, integrate theory and practice, and apply knowledge and skills to develop a viable solution to a defined problem" (Savery, 2006, p. 12). Reviewing Barrows' (n.d.) Generic PBL Essentials, Savery (2006) indicated that collaboration is essential in effective learning in PBL (p. 13). To address collaborative learning, a PBL curriculum places primary emphasis on group work.

Group work may generate "a realistic team-based working environment and [foster] a community of practice" (Neville \& Britt, 2007, p. 231). Chang (2010) indicated that when the groups develop a positive identity among the members, a joyful, supportive classroom climate may hence be created. Such classroom atmosphere can be referred to group cohesiveness. Cohesive groups usually learn efficiently because of the peers' sharing information and ideas (Senior, 1997; Chang, 2010). "Members of a cohesive group show a strong connection by sharing ideas with each other, participating in group-related activities, or working easily together" (Dörnyei \& Murphey, 2003, cited from Chang, 2010, p. 131). Based on such group dynamic theoretical background, the PBL pedagogy emphasizes the construction of a learning scaffold to facilitate peer collaboration and further assumes that the learners can be supported by teachers and peers in group work.

Literacy education can generate effective outcomes by means of social interaction. According to Vygotsky's social learning theory, an individual who participates in social events may eventually construct a knowledge base in a mutually supportive environment. As Kaufman (2004) explained, "children's thinking and meaning-making is socially constructed and emerges out of their social interactions with their environment" (p. 304). In a PBL classroom, the students are organized to work in small groups. Small groups may construct a scaffolded learning environment. Lin (2017a) recommended that each group be composed of both proficient and less-proficient learners; during the process of completing the problem-solving task, proficient learners may model the successful learning outcome. The learners in the small groups often work together to search for information, and read the data to identify potential solutions to the problem. Moreover, group work may offer students opportunities to share personal expertise, and further stimulate interpersonal communicative activities (Lin, 2017a). In this way, every learner may engage in a mutually supportive environment.

The present study assumes that learner attitudes may mediate the tasks of reading. Mutual support in group work may be beneficial for the development of active learning attitudes. Regarding the importance of mutual support in PBL, Lin (2017a) emphasized that "interpersonal interaction can be embedded into English instruction" (p. 19). Small group scaffolding in a PBL classroom may stimulate active learning. The scaffolding may generate intense feelings among group members, supporting each other to complete the assigned tasks in a timely manner. In a traditional teacher-lecture classroom, on the whole, the teacher usually takes the responsibility for delivering lectures to all of the students. However, these lectures may not be effectively received by the learners. Moreover, the individual students may not be 
eager to complete the assignments.

I generated a figure to illustrate small-group interaction in a PBL English course (see Figure 1 for the small-group interaction framework). Wenger (1998) stated that small-group learning provided the group members with a joint enterprise. The participation in such a joint enterprise may "[develop] the shared repertoire and skills of the community" (Neville \& Britt, 2007, p. 231). Lin (2017a) proposed a five-stage PBL teaching scheme, starting with confronting the problem, then examining the problem, re-examining the problem, and finally reviewing the problem through presenting the solutions. As shown in Figure 1, small groups are centered on the problem-solving cycle. In each stage, small groups listen to the teacher's directions of how to implement each stage task, and afterwards undertake group activities. The present study assumes that every learner likely participated in most aspects of the learning activities through the small-group management.

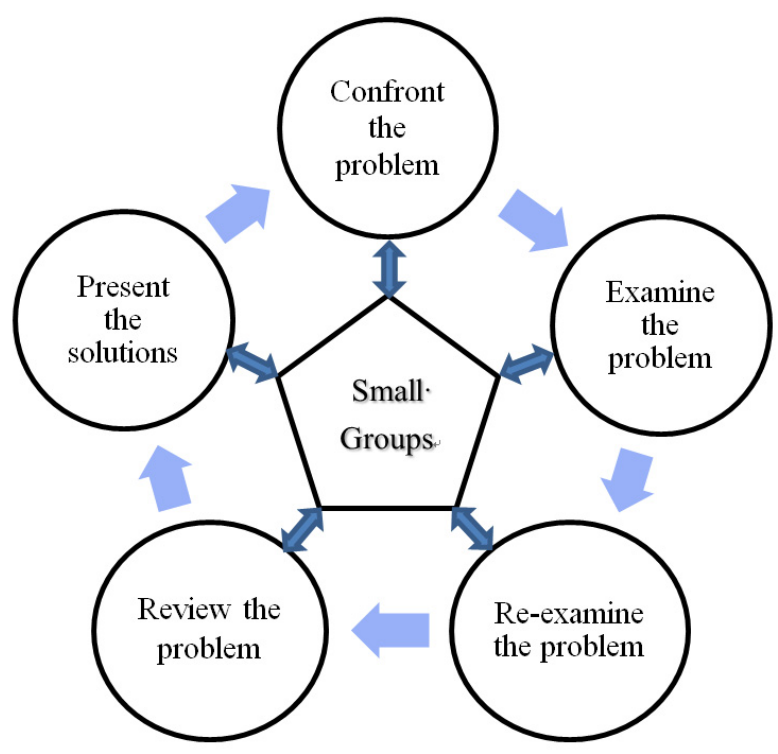

Figure 1. The Problem-based learning instructional model for teaching English as a second/foreign language

\subsubsection{Previous PBL Research Outcomes}

As Albanese (2000) indicated, the essential theoretical advantage of PBL is contextual learning (i.e., receiving knowledge in the context of how it raises the possibility that new knowledge and skills are useful in actual practice). Regarding the content learning, previous empirical studies have tended to support the hypothesis that PBL is effective for knowledge construction and retention (Dods, 1997; Gijbels, Dochy, Van den Bossche, \& Segers, 2005; Hmelo, 1998; Mergendoller, Maxwell, \& Bellisimo, 2006; Schmidt, 1993; Schmidt et al., 1996). In the field of education, PBL has been widely applied to enhance students' ability to apply knowledge from the classroom to the real world (Poikela \& Poikela, 2005).

Regarding learner affect, PBL is also effective in terms of fostering students' motivation and engagement in learning (Azman \& Shin, 2012; Norman \& Schmidt, 2000; Bosuwon \& Woodrow, 2009), students' social interaction and communication skills (De Grave, Schmidt, \& Boshuizen, 2001; Duch, Groh, \& Allen, 2001; Van Boxtel, Van der Linden, \& Kanselaar, 2000), responsibility for learning (Peters, 2010), and self-directed learning (Blumberg, 2000; English \& Kitsantas, 2013; Kivela \& Kivela, 2005; Sungur \& Tekkaya, 2006). It has been found that self-regulation is highly related to students' academic performance (English \& Kitsantas, 2013; Zimmerman, 2008, 2013). As English and Kitsantas (2013) explained, self-regulated learners are able to self-monitor and self-evaluate their learning. When implementing a teaching technique, the optimal instructional outcome is the lasting effect. Several studies have reported that the students who participated in the PBL program extended their learning after the treatment, and enjoyed learning (Doucet, Purdy, Kaufman, \& Langille, 1998; Lin, 2017a; Torp \& Sage, 2002). Conducting the PBL questionnaire survey, Lin (2017b) stated that the PBL approach significantly fostered EFL learners' active learning attitudes. The results of the reviewed studies on learner affect show that PBL likely provides a format for the development of the learners' AELAs. This learner affect can closely align with specific features of active learning. The present study examined the effects of PBL on the learners' AELAs. 


\subsection{Active English Learning Attitudes}

Attitude is an essential affective factor that has great impact on L2 learning. Positive attitudes may empower the learner to learn language effectively (Merisuo-Storm, 2007; Oxford, 1990). The current study focused on examining English learners' AELAs because learners' reading attitudes play an essential role in developing their lifelong reading skills (Lazarus \& Callahan, 2000). Learners' active engagement, involvement, or participation in discussion and interaction can maximize the effects of learning (Lin, 2011). Therefore, the activeness of readers' attitudes should be stressed. In the current study, most of the participants were undergraduate students preparing for their future career in international corporations. In an empirical study, AELAs can be inferred from the following three attributes, reading attitudes, autonomous learning, and intercultural communication.

First, AELAs can refer to a reader's feelings. Several researchers have examined reading attitudes in the field of L2 reading research. Tracing back to 40 years ago, Alexander and Filler (1976) defined reading attitude as "a system of feelings related to reading which causes the learner to approach or avoid a reading situation" (p. 1, cited in Yamashita, 2007). With a focus on the reader's affect, Smith (1990) referred to reading attitudes as "a state of mind, accompanied by feelings and emotions that make reading more or less probable" (p. 215). The readers' feelings about reading defined in these two definitions are closely related to motivation or interest in reading.

Furthermore, the definition of AELAs can be interpreted from the theoretical backgrounds of autonomous learning. Almost three decades ago, Holec (1981) defined autonomy as the ability to take charge of one's own learning when learning a foreign language. Boud (1988) further elaborated it from the angle of an individual's inner restraints, and interpreted it as "the property of a state to be self-ruling or self-governing" (p. 18). The concept of autonomous learning that learners need to become independent of teachers, to self-assess, to monitor their own learning, and eventually to complete learning projects autonomously outside the classroom has also been widely accepted in language education (Benson, 1997). Some empirical research has further listed the attributes of autonomous learning to manipulate the quantitative analysis. For example, Chan, Spratt, and Humphreys (2002) examined Chinese-speaking students' views on their responsibility, decision-making abilities in learning English, and their motivational level. In general, learners can be educated with a sense of taking responsibility for their own learning and self-regulation.

In addition, intercultural communication can be considered as a focal part of AELAs. The present study focused on investigating university students' attitudes, as most of them were learning English to prepare themselves well for entering an international workplace. The students needed to enhance their ability to communicate with people from different countries. With an emphasis on L2 communicative functions in various social contexts, AELAs can be considered as involving the following elements: communication inside and outside the classroom, and communication across different cultural groups who speak different mother languages. Underpinning learner communication willingness, Yashima, Zenuk-Nishide and Shimizu (2004) examined motivational/attitudinal and affective variables by synthesizing the questionnaire items from other studies. The subscales composed in their study included motivational intensity, desire to learn English, interest in foreign affairs, and communication inside and outside the classroom. These dimensions are closely related to the factors reviewed in the above section, so their questionnaire framework was adopted in the current study.

From reviewing the literature, some gaps were identified. First, the PBL approach has been widely applied to various education areas, but there is a lack of explicit research on second/foreign language education. Second, although reading attitudes have been discussed, few studies have attempted to describe EFL learners' AELAs, or needless to say, have examined the effectiveness of the PBL approach on AELAs. The following research questions were therefore addressed:

1. Does the PBL approach significantly improve the university students' English reading comprehension ability and reading comprehension strategy use in terms of the total score and the subscores of the reading comprehension post-test?

2. Does the PBL approach significantly foster the university students' active English learning attitudes in terms of the responses to the whole questionnaire and the subscales?

3. Is there any significant relationship between the university students' active English learning attitudes and their reading comprehension?

4. How do the PBL participants complete the task of problem solving?

\section{Method}

\subsection{Research Design}

This study adopted a pre- and post-test research design. Two intact classes were randomly assigned to the experimental and control treatment conditions. The experimental group received PBL instruction, whereas the control group did not. 
Pre- and post-test data were analyzed to determine the impact of the independent variable instructional condition (PBL or non-PBL) on the dependent variables, student RC ability, and the application of RC strategies. Prior to the treatment, all participants took the RC pre-test. One week after the treatment, all participants took the RC post-test, and completed the AELAs questionnaire.

Both the PBL and non-PBL treatment participants read two sets of video-based materials with different topics, spending 5 weeks on each video clip. The two treatments were conducted within the 5 weeks as a cycle. When the second set of materials was presented, the two treatments were repeatedly conducted within another 5 weeks as a cycle. The treatment section therefore covered 10 weeks of two 50-minute periods per week.

\subsection{Participants}

Two classes of university students were recruited for this study. At the time of the study, they were taking an advanced English reading course to fulfill their foreign language requirement. Their mother language is Mandarin and they were learning English as a foreign language. Their English ability was categorized as intermediate level by the university based on their score for English in the General Scholastic Ability Test held by the College Entrance Examination Center in Taiwan. They had already learned EFL for 10-12 years. This group of participants consisted of undergraduate students. Furthermore, $26.78 \%$ were sophomores $(n=15), 25 \%$ juniors $(n=12)$, and $48.21 \%$ seniors $(n=27)$.

The two intact classes were randomly assigned to either the experimental $(n=26)$ or control $(n=30)$ group. The two groups of participants took the RC pre-test to measure whether there was a significant difference between the two groups in terms of their RC ability. The Independent Sample $t$-test statistical results show that the PBL and non-PBL groups did not differ significantly on the pre-test $(t=-0.196, \mathrm{p}>.05)$, indicating that the participants' RC ability was similar prior to the instructional treatment.

\subsection{Research Materials}

The research materials focused on two topics: dolphins and interesting people of the world. Reading materials related to these two topics were selected as research materials. For example, the reading materials on the theme of dolphins consisted of the Footprint Reading Library reader, Cupid the Dolphin (Waring 2009), and one unit of the textbook, The Dolphin (Lee, 2005). The reader selected from the Footprint Reading Library was graded as intermediate level with 1,600 headwords. All selected materials were non-fiction.

Samples of the problems and the websites used in the PBL treatment are as follows:

The problems: What do you know about dolphins?

If a dolphin is stranded on the beach, how can we save it?

The websites: http://www.dolphins-world.com/ (retrieved May 5, 2017)

http://www.oceanlink.info/ocean_matters/dolphin.html (retrieved May 5, 2017)

\subsection{Instructional Treatment}

\subsubsection{PBL Treatment}

The PBL instructional procedure was constructed with the problem (see Table 1 for the teaching scheme) and was conducted in small-group settings. Table 1 presents the PBL teaching scheme, which was adopted from the previous studies by Lin $(2016,2017 \mathrm{a}, 2017 \mathrm{~b})$. The scheme specifically featured small-group discussion in and out of class. To ensure the normal distribution of English reading proficiency in each group, the participants were grouped by the instructor based on their scores on the RC pre-test to form heterogeneous groups. Each group selected a leader who was responsible for showing the members how to make sense of the content of the article, organized the meetings for collaborative learning, and distributed jobs to the other group members. The students worked together in their groups and were encouraged to work together to make decisions about every task. They kept in touch with each other via the in-class and after-class meetings.

The 5-week treatment scheme was presented. In the first week, the instructor used 30 minutes to lead the participants to view or read the assigned video material. The instructor asked the participants to identify the main ideas of some sections and the meanings of some vocabulary from the text context. In this phase, the instructor intended to make sure that the participants understood the content of the assigned video materials. In the remaining 3 weeks, each group had a discussion and read English supplementary materials to search for information to solve the problem. Afterwards, the instructor asked the participants to use both the assigned materials and the collected information to solve the problem. In the last week, each group took turns presenting their solutions, and the instructor provided the feedback to each group. 
In the section of small-group discussion, the instructor stayed with each group for a short period of time, ensuring that all members had equal opportunity to participate and hence contribute their ideas at some point in each discussion session. To maintain the flow of the discussion, the participants could use Chinese to express their ideas. The participants of each group also met each other after class to complete the assigned tasks.

Table 1. PBL curriculum of a 5-week cycle

\begin{tabular}{|c|c|c|c|}
\hline Week & Procedure & Weekly Schedule & \\
\hline \multirow[t]{2}{*}{1} & \multirow[t]{2}{*}{$\begin{array}{l}\text { Confronting the } \\
\text { problem }\end{array}$} & In class & $\begin{array}{l}\text { The teacher proposes and explains the problem in class. } \\
\text { The members of each group choose the task they want to take on. } \\
\text { Each group discusses the problem and analyzes the components of } \\
\text { the problem. }\end{array}$ \\
\hline & & Out of class & $\begin{array}{l}\text { Each group discusses the problem and reads the assigned materials } \\
\text { together. }\end{array}$ \\
\hline \multirow[t]{2}{*}{2} & \multirow[t]{2}{*}{$\begin{array}{l}\text { Examine the } \\
\text { problem }\end{array}$} & In class & $\begin{array}{l}\text { The teacher asks each group to report how they allotted the jobs to } \\
\text { complete the problem-solving task. } \\
\text { The teacher asks each group to examine the problem by identifying } \\
\text { the sub-concepts. } \\
\text { Each group is engaged in a discussion, which includes reviewing } \\
\text { the problem in detail, confirming the scope of the answers, and } \\
\text { formulating the action plan. }\end{array}$ \\
\hline & & Out of class & Each group performs data collection and reads the information. \\
\hline \multirow[t]{2}{*}{3} & \multirow[t]{2}{*}{$\begin{array}{l}\text { Re-examining the } \\
\text { problem }\end{array}$} & In class & $\begin{array}{l}\text { The teacher asks each group to examine the problem again and } \\
\text { analyzes whether there are extra components. } \\
\text { Each group is engaged in a discussion of the collected information. } \\
\text { Each group reads the assigned materials to identify the relationship } \\
\text { between the concepts by drawing a concept map. }\end{array}$ \\
\hline & & Out of class & $\begin{array}{l}\text { Each group continues to have a discussion, searches for extra } \\
\text { information, and reads the information. }\end{array}$ \\
\hline \multirow[t]{2}{*}{4} & \multirow[t]{2}{*}{$\begin{array}{l}\text { Reviewing } \\
\text { problem }\end{array}$} & In class & $\begin{array}{l}\text { The teacher asks each group to review the problem and decides } \\
\text { whether they need to add extra information. } \\
\text { Each group reads all materials to construct an outline, which } \\
\text { contains the headings representing main ideas and the subheadings } \\
\text { showing the details. }\end{array}$ \\
\hline & & Out of class & $\begin{array}{l}\text { Each group prepares an oral presentation by synthesizing the } \\
\text { collected information. }\end{array}$ \\
\hline 5 & $\begin{array}{l}\text { Presenting } \\
\text { solutions }\end{array}$ & In class & $\begin{array}{l}\text { The teacher asks each group to report on their meeting outside the } \\
\text { class. } \\
\text { Each group presents the solutions to the problem with PowerPoint } \\
\text { slides as a visual aid. } \\
\text { Each group evaluates and writes comments on other groups' } \\
\text { presentations. } \\
\text { The teacher provides recommendations to each group. }\end{array}$ \\
\hline
\end{tabular}

Note. Some weekly statements were cited from Lin (2017a, pp. 23-24)

\subsubsection{Non-PBL Treatment}

The non-PBL group did not receive any PBL training and did the tasks individually rather than in groups. The instruction component of the control condition was structured as a series of reading instructional sections in the following sequence of activities: topic knowledge activation, article reading aloud, text translation and interpretation, explanations of sentence structure and vocabulary, and video viewing. At the end of each period, each participant did some grammar and vocabulary exercises. The teaching model was teacher-centered presentation and interpretation. If the participants had any difficulties, the teacher would help them. The teacher also offered feedback on the participants' responses, and made corrections to the participants' exercises.

\subsection{Instruments}

\subsubsection{Reading Comprehension Pre- and Post-tests}

Lin (2017b) adopted the passages from Pauk's textbook (2002) at the advanced level, presenting the steps of how to select passages with the same level of text difficulty and how to establish the validity of the pre- and post-tests. The present study measured the participants' RC ability and hence I adopted the same passage format. 
The passages used in this study were different from those used in Lin (2017b). This is because the present study additionally examined the participants' usage of RC strategies. I decided to use the passages with a lower level of text difficulty. Following the steps in Lin's study (2017b), I selected the passages at the intermediate level from Pauk's (2002) textbook. In this study, the RC pre- and post- tests included the same six passages.

The present study adopted Pauk's model to investigate the participants' strategy usage to comprehend English passages. Pauk (2002) composed a series of RC strategies for understanding a passage. Each passage was designed with six questions, representing six types of RC strategies, namely identifying main ideas, synthesizing the subject matter of a passage, drawing conclusions from a passage, identifying the devices used by the writer to make the passage interesting, searching for supporting details, and decoding the meaning of the vocabulary in the context.

One correct response was evaluated with 1 point. The maximum score for each strategy was therefore 6 points, and the maximum score for each test was 36 points ( $=6$ passages $\mathrm{x} 6$ items), with each correct response worth 1 point. The reliability of the pre- and post-tests was satisfactory at $\alpha=.72$ and $\alpha=.71$, respectively.

The totaled score of each question item on the RC post-test were further regarded as that of each strategy usage. The totaled score of each question item was used to analyze the two groups' application of RC strategies. As shown in Table 2 , the relationships between the subscores of the six strategies and the totaled score of the RC post-test were significant. Correlation is significant at the 0.01 level (2-tailed).

Table 2. Correlations between the score of each strategy and the total score on the reading comprehension post-test

\begin{tabular}{llllllll}
\hline Variables & Correlations/Sig & S1 & S2 & S3 & S4 & S5 & S6 \\
\hline Total & Pearson & $.814^{* *}$ & $.757^{* *}$ & $.767^{* *}$ & $.579^{* *}$ & $.624^{* *}$ & $.594^{* *}$ \\
& Sig. (2-tailed) & .000 & .000 & .000 & .000 & .000 & .000
\end{tabular}

Note. $\mathrm{S} 1$ = identifying main ideas; $\mathrm{S} 2$ = synthesizing the subject matter of a passage; $\mathrm{S} 3=$ drawing conclusions from a passage; $\mathrm{S} 4=$ identifying the devices used by the writer to make the passage interesting; $\mathrm{S} 5=$ searching for supporting details, and S6 $=$ decoding the meaning of the vocabulary in the context. ${ }^{* *} p<.01 ;{ }^{*} p<.05$

\subsubsection{The Active English Learning Attitudes Questionnaire}

The AELAs questionnaire adopted four subscales from Yashima, Zenuk-Nishide, and Shimizu's (2004) study, consisting of 20 items. The titles of the four subscales were coded as Motivational Intensity (MI, 6 items), Desire to Learn English (DLE, 6 items), Interest In Foreign Affairs (IIFA, 2 items), and Communication Inside and Outside the Classroom (CIOC, 5 items). Ratings were all recorded on 7-point scales. The objectives of the subscales were presented in the study by Yashima et al. (2004, pp. 128-130). High Cronbach's alphas were reported in their study in which the same subscales were used for a large sample. In this study, the reliability of the questionnaire responded to by 56 participants was satisfactory at $\alpha=.73$.

I administered a pilot study to ensure the clarity of the instructions, the wording of the items, and the questionnaire format. Some modifications were made. First, the subscale of CIOC, originally named Frequency and amount of communication in English, was a 10-point scale. To reduce the participants' confusion, it was changed to a 7-point scale. Second, due to the fact that the control group worked individually, the wording of the item "I participated in classroom activities such as pair work" was slightly modified to "I participated in classroom activities."

To explore the participants' active English learning out of class, I assumed that the participants who had active attitudes toward reading may spend more time reading English texts than those who did not have such attitudes. I therefore added one question item, "How much time did you spend reading English academic and non-academic texts every week during the treatment?"

The results of Pearson correlation analysis show that there are positive significant relationships between the four subscales and the whole questionnaire (see Table 3). The Pearson correlation coefficients also show that the strength of association between the variables is medium and high.

Table 3. Correlations between the subscales and the total questionnaire

\begin{tabular}{llllll}
\hline Variables & Correlations/Sig & MI & DLE & IIFA & COIC \\
\hline Total & Pearson & $.664^{* *}$ & $.746^{* *}$ & $.740^{* *}$ & $.637^{* *}$ \\
& Sig. (2-tailed) & .000 & .000 & .000 & .000
\end{tabular}

Note. $\mathrm{MI}=$ Motivational Intensity; DLE $=$ Desire to Learn English; IIFA $=$ Interest In Foreign Affairs; COIC = Communication Inside and Outside the Classroom. ${ }^{* *} p<.01 . n=56$ 


\subsubsection{Self-reports}

To understand how the participants in the PBL group completed the task of problem solving, the participants were asked to answer the following question: What kind of task did you do in your group?

\subsection{Data Analysis}

The present study aimed to investigate whether the PBL approach could improve the participants' RC ability and their active English learning. To answer the research questions, independent sample $t$ tests and paired sample $t$ tests were conducted for between-group and within-group comparisons. The independent variable was the group (experimental and control) and the dependent variables consisted of the scores on the RC pre- and post-tests and the scores on the AELAs questionnaire. The scores on the RC post-test of the two groups were used to evaluate the learning outcomes of each treatment and the RC strategy usage by each group.

\section{Results and Discussion}

\subsection{The PBL and Non-PBL Groups' Reading Comprehension Post-test}

The first research question was to investigate whether the PBL approach significantly improved the university students' English RC ability and strategy use in terms of the total score, and the six subscores of the RC post-test.

\subsubsection{The PBL and Non-PBL Groups' Reading Comprehension Performance}

Table 4 provides the descriptive statistics (number of valid cases, means and standard deviations) of the PBL and non-PBL groups' scores on the RC post-test. The Independent Sample $t$ test was conducted to compare the effectiveness of the two instructional treatments. The PBL group's total mean score on the post-test $(M=28.15)$ was higher than that of the non-PBL group $(M=26.20)$, and the independent sample $t$ test yielded a significant result between the two groups in the total score of the RC post-test $(t=2.206, p<.05)$. The results show that the PBL group comprehended the passages better than the non-PBL group.

Table 4. PBL and non-PBL groups' independent sample $t$-test results on the reading comprehension post-test

\begin{tabular}{lcccccccc}
\hline & \multicolumn{2}{c}{ PBL $(n=26)$} & & \multicolumn{2}{c}{ Non-PBL $(n=30)$} & & \\
\cline { 2 - 3 } & Mean & SD & & Mean & SD & $t$ & $p$ \\
\hline MAIN & 5.04 & 1.00 & & 4.83 & 1.08 & .747 & .458 \\
SUBM & 5.27 & 1.08 & & 4.17 & 1.23 & 3.567 & $.001^{*}$ \\
SDET & 5.35 & .75 & & 4.63 & 1.69 & 2.086 & $.043^{*}$ \\
CONC & 4.08 & 1.06 & & 3.50 & 1.66 & 1.575 & .122 \\
DEVI & 4.38 & 1.24 & & 4.93 & 1.26 & -1.644 & .106 \\
VOCA & 4.04 & .87 & & 4.213 & 1.04 & & -.371 & .712 \\
Total & 28.15 & 3.51 & & 26.20 & 3.06 & & 2.206 & $.032^{*}$ \\
\hline
\end{tabular}

Note. MAIN = identifying main ideas; SUBM $=$ synthesizing the subject matter of a passage; SDET $=$ searching for supporting details; $\mathrm{CONC}=$ drawing conclusions from a passage; $\mathrm{DEVI}=$ identifying the devices used by the writer; $\mathrm{VOCA}=$ decoding the meaning of the vocabulary in the context; $\mathrm{PBL}=$ problem-based learning; non-PBL $=$ non-problem-based learning. ${ }^{*} p<.05$

To respectively address the effect of the PBL and non-PBL treatments on the participants' reading comprehension, a paired $t$ test was conducted to examine the differences between the test scores within groups. The mean score $(M=$ $28.15, \mathrm{SD}=3.532)$ of the PBL group's post-test was higher than that of its pre-test $(M=24.65, \mathrm{SD}=3.506)$. There was a significant difference between the PBL group's pre- and post-tests $(t=-3.586, p=.001)$. That is, the participants in the PBL group made significant progress in their RC ability after the instructional treatment. For the non-PBL group, the mean score of the post-test $(M=26.2, \mathrm{SD}=2.976)$ was higher than its pre-test mean score $(M=24.83, \mathrm{SD}=3.270)$; however, the mean scores did not differ significantly $(t=-1.693, p=.096)$. The results of the paired $t$ test further confirmed that the participants in the non-PBL group did not show significant improvement in their RC ability after engaging in the traditional reading treatment.

\subsubsection{The PBL and Non-PBL Groups' Reading Comprehension Strategy Use}

In addition, the $t$-test results also revealed that there were significant differences between the two groups' application of $\mathrm{RC}$ strategies, such as the $\operatorname{SUBM}(t=3.567, p<.05)$, and the $\operatorname{SDET}(t=2.086, p<.05)$ strategies. As shown in Table 4 , 
the mean scores of the two strategies in the PBL group's post-test are higher than those in the non-PBL group, indicating that the PBL participants' use of the SUBM and SDET strategies was better than that of their counterparts.

This is most likely because, during the treatment session, the PBL participants were required to organize an outline and the main points from the collected data and also to identify the details for potential solutions. As Pauk (2002) explained, the SUBM strategy helps the reader concentrate. At the beginning stage of reading the passage, the reader may instantly ask him/herself, "What is the subject matter of this passage?" In this way, this type of skimming task offered the participants the opportunity to concentrate on reading through the lines of text and quickly focus on the subject matter.

In addition, the task of searching for possible solutions to the problems may have resulted in the PBL participants' successful application of the SDET strategy. In general, the articles were likely composed of details that supported the main ideas. During the reading process, the readers likely confronted various forms of details, such as examples, explanations, descriptions, definitions, comparisons, contrasts, exceptions, analogies, similes, and metaphors (Pauk, 2002). The readers need to practice reading various forms of supporting details. In the PBL treatment, although the instructor did not provide explanations of these types of details, the participants sufficiently exposed themselves to reading English text in a variety of genres and to identify how these details were used to support the main ideas. During the treatment, the participants likely took apart the articles sentence by sentence. In such a situation, they had a chance to practice reading how these sentences linked with each other to compose a coherent passage.

In general, the results of the present study are consistent with the previous research on English reading comprehension, indicating that the PBL approach significantly improved the EFL learners' RC ability (Lin, 2017b) and further revealing that PBL significantly enhanced the learners' SUBM and SDET strategies. Consistent with previous research (Hmelo, 1998; Poikela \& Poikela, 2005; Schmidt et al., 1996), the present study also offers evidence that the PBL approach has positive outcomes for learning. The significant results of the RC post-test can be attributed to sufficient exposure to the environment of English reading in the PBL treatment. During the treatment, the PBL participants needed to read the information and practice reading skills not only in class but also after class. In 10 weeks of treatment, the PBL participants obviously improved their RC ability. In addition, the extensive reading outside the class offered the PBL group an opportunity to practice RC strategies. Reading a huge amount of data and looking for the answers to the problems may have tapped different levels of strategy usage such as grasping main ideas, constructing subject matter of what has been read, skimming unrelated details, and identifying the essential details for responding to the problem. Given the amount of strategy-usage practice that the PBL group completed during the treatment, it logically follows that they made progress in their RC strategy usage and hence were likely to improve their reading comprehension.

By contrast, the non-PBL group may not have particularly focused on the learner-centered activities in class, and there was a lack of self-directed learning outside the classroom. Although they read the assigned materials and received full interpretations from the teacher, they did not undergo any self-rehearsal in their minds. As a result, they may have relied on the teacher to interpret the meanings of the vocabulary and to understand the content of the text.

\subsection{PBL and Non-PBL Groups' Active English Learning Attitudes}

The second research question was to investigate whether the PBL approach significantly fostered the university students' active English learning attitudes in terms of their responses to the whole questionnaire and the subscales.

The participants' questionnaire responses were ranked from Strongly agree (a rating of 7) to Strongly disagree (a rating of 1). Table 5 summarizes the descriptive statistical results of the mean scores of the two groups' responses to the AELAs questionnaire after the treatment. The data in Table 3 show that the total mean score of the PBL group $(M=$ 4.71) was higher than that of the non-PBL group $(M=4.39)$. Furthermore, the Independent Samples $t$ tests revealed a significant difference between the two groups $(t=2.36, p<.05)$, indicating that the PBL participants exhibited a significantly higher degree of active learning attitude toward English than the non-PBL participants after the treatment.

Table 5. PBL and non-PBL groups' independent sample $t$-test results on the active English learning attitudes questionnaire

\begin{tabular}{|c|c|c|c|c|c|c|}
\hline & PBL ( & & Non-P & 30) & & \\
\hline & Mean & SD & Mean & SD & $t$ & $p$ \\
\hline MI & 5.22 & .62 & 4.80 & .73 & 2.299 & $.025 *$ \\
\hline DLE & 5.27 & .73 & 4.74 & .98 & 2.335 & $.023 *$ \\
\hline IIFA & 4.02 & .64 & 3.99 & .56 & .143 & .887 \\
\hline COIC & 4.64 & .85 & 4.18 & .81 & 2.065 & $.044 *$ \\
\hline Total & 4.71 & .50 & 4.39 & .50 & 2.363 & $.022 *$ \\
\hline
\end{tabular}

Note. $\mathrm{MI}=$ Motivational Intensity; DLE = Desire to Learn English; IIFA = Interest In Foreign Affairs; COIC $=$ Communication Inside and Outside the Classroom; $\mathrm{PBL}=$ problem-based learning; non-PBL = non-problem-based learning. $* p<.05$ 
Regarding the four subscales, the PBL group's four mean scores are consistently higher than those of the non-PBL group (see Table 5). The PBL group's mean scores of the five subscales are all over 4. The DLE dimension was rated with the highest mean scores $(M=5.27)$ and MAIN, the second $(M=5.21)$, indicating that the PBL participants' desire to learn English increased obviously after receiving the treatment. Furthermore, Independent samples $t$ tests showed that there were significant differences between the two groups in the subscales of MAIN $(t=2.27, p<.05)$, DLE $(t=2.34, p$ $<.05)$ and CIOC $(t=2.07, p<.05)$. These results show that after receiving PBL training, the participants' motivation intensity, their desire to learn English, and communication inside and outside the classroom were significantly higher than those of the participants of the non-PBL group.

Given that the PBL approach had a positive impact on fostering the PBL participants' AELAs, individual items of the questionnaire were further examined to understand in which specific aspect the PBL participants improved their active learning. Table 6 presents the independent samples $t$-test results of the two groups in terms of 19 individual items. Out of these 19 items, there were six significant differences, indicating that the PBL group's mean scores were significantly higher than those of the non-PBL group. An overall trend of improvement of AELAs was evident for the PBL group.

Table 6. Significant differences between the PBL and non-PBL groups for individual items

\begin{tabular}{llll}
\hline $\begin{array}{l}\text { Subscale (Item } \\
\text { No.) }\end{array}$ & Item Statement & $t$ & $p$ \\
\hline MI (6) & $\begin{array}{l}\text { After I graduate from college, I will continue to study English and } \\
\text { try to improve. }\end{array}$ & 4.496 & .000 \\
DLE (8) & $\begin{array}{l}\text { I read English newspapers or magazines outside my English course } \\
\text { work. }\end{array}$ & 7.148 & .000 \\
DLE (12) & I find studying English more interesting than other subjects. & 2.842 & .006 \\
IIFA (13) & I often read and watch news about foreign countries. & 4.351 & .000 \\
COIC (15) & I volunteered to answer or ask questions in class. & 2.299 & .025 \\
COIC (16) & I answered when I was called upon by the teacher. & 2.892 & .006 \\
\hline
\end{tabular}

Note. $\mathrm{MI}=$ Motivational Intensity; DLE $=$ Desire to Learn English; IIFA = Interest In Foreign Affairs; COIC $=$ Communication Inside and Outside the Classroom; $\mathrm{PBL}=$ problem-based learning; non-PBL $=$ non-problem-based learning. ${ }^{*} p<.05$

The following discussion of the significant results is divided into three aspects. First, the PBL participants had strong motivation to improve their English after school (Item 6) and also had great interest in learning English (Item 12). The significant results demonstrate active learners' characteristics consistent with some characteristics identified in the previous studies, such as being highly motivated and being interested and enthusiastic about what is learnt (Azman \& Shin, 2012; Norman \& Schmidt, 2000; Bosuwon \& Woodrow, 2009). The significant results can be attributed to the hands-on activity of solving the real-world problems. The problems designed for the PBL treatment formulated scenarios, which likely activated a series of participants' prior knowledge and related life experiences. The problem-solving process was seemingly related to the participants' dealing with their own affairs. In addition, the hands-on activity involved the participants in planning the learning schedule and selecting the learning materials by themselves. The hands-on activity could promote the participants' engagement with English learning. As a result, they demonstrated strong enthusiasm for learning English.

In addition, Items 6 and 12 pertain to investigating the participants' self-regulation. In the situations of "after graduating from college" and "outside of the English course," the PBL participants responded that they still continue to learn English. This finding is similar to those obtained in previous studies (Blumberg, 2000; English \& Kitsantas, 2013; Kivela \& Kivela, 2005; Sungur \& Tekkaya, 2006), indicating that PBL participants outperform their counterparts in independent learning and self-directed learning.

Moreover, the PBL participants undertook extensive reading activities (Item 8), and also read some articles related to foreign countries (Item 13). PBL facilitated the participants' reading, and this result can explain the PBL participants' significant achievements in the RC post-test. In this study, the PBL participants tried different ways to search for information on the Internet and made use of every opportunity to identify the solutions to the problem. These tasks required reading skills. In this way, the participants frequently practiced English reading.

The results of both Items 15 and 16 show that the PBL participants exhibited significantly stronger communication skills than the non-PBL participants. This result is consistent with that concluded in previous studies (De Grave, Schmidt, \& Boshuizen, 2001; Duch, Groh, \& Allen, 2001; Van Boxtel, Van der Linden, \& Kanselaar, 2000). This is probably because the PBL participants have opportunities to practice social interaction in small groups. Investigating the activities their PBL participants enjoyed the most, Azman and Shin (2012) reported that the highest percentage of the respondents enjoyed the collaboration and cooperation among group members; the participants expressed that they enjoyed sharing different ideas with their partners when solving the problem. In this study, the PBL participants joined 
small group discussions in and out of the class, during which each group member frequently expressed his/her opinions and had conversation with each other. Thus, the small group scaffolding likely generated a collaborative environment so that each participant could practice his or her communication skills.

Regarding the factor "time spent on English reading," the PBL group on average spent 4.92 hours (SD = 1.47) reading English texts during the treatment compared with the non-PBL group's 2.95 hours $(\mathrm{SD}=2.55)$. The statistical results show that there was a significant difference between the two groups $(t=-3.472, p=.001)$. This result indicates that the PBL participants obviously extended their reading in English after class. Furthermore, the data in Figure 2 reveal that all PBL participants spent at least 2 hours reading English materials and up to 16 PBL participants spent over 5 hours. On the other hand, seven participants in the non-PBL group did not spend any time or spent less than 1 hour reading English. It can be noted that there were two extremes cases in the non-PBL group who spent 8 and 12 hours studying English every week. They explained that they were motivated by their upcoming attendance of a proficiency test. The results of the present study are in concordance with those concluded by Lin's (2017b) empirical study, indicating that the PBL approach activated the students' active learning. In general, the results virtually verify that the PBL pedagogy propels EFL learners' AELAs.

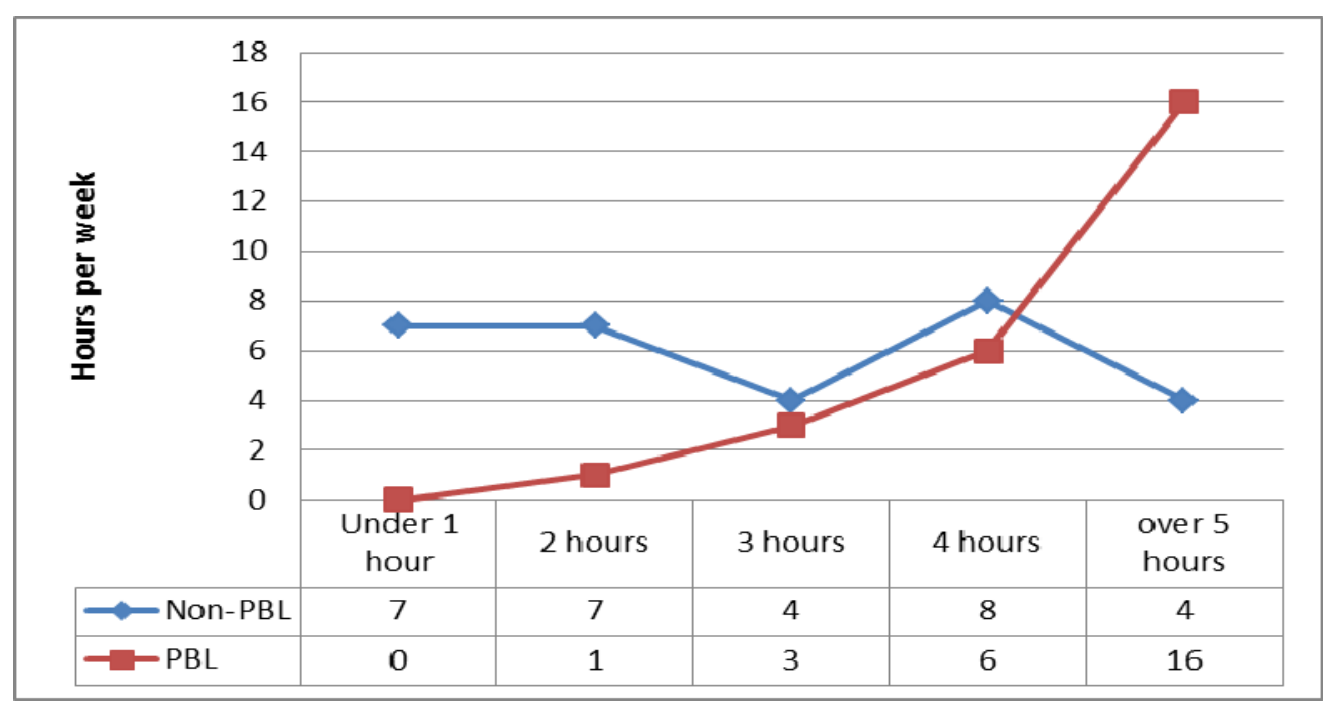

Figure 2. Two groups of participants' English reading time per week

4.3 Correlations among the Active English Learning Attitudes Questionnaire and the Reading Comprehension Posttest Variables

The third research question was to investigate whether there was any significant relationship between the university students' active English learning attitudes and their reading comprehension.

The Pearson correlation analysis was conducted to examine the correlations between the variables for the two treatments, as shown in Table 7. The statistical results showed that there were significant correlations between the total score on the RC post-test, and the total and the four subscales of the AELAs questionnaire.

Regarding the PBL group, the whole questionnaire is strongly related to the RC post-test score $(r=.773)$. Correlation is significant at the 0.01 level (2-tailed). In addition, the mean scores of the four subscales are significantly related with the RC post-test score, and the strength of association between the variables is medium. In general, the results suggest that after receiving the PBL treatment, the PBL participants' AELAs are significantly related to their reading comprehension; moreover, their MAIN, DEL IIFA and COIC are also significantly correlated with their performance on the RC post-test.

Regarding the non-PBL group, there is no significant relationship between the AELAs and RC $(r=.064)$. Among the mean scores of the four subscales, correlations of MAIN, DEL, and IIFA do not reach significant level. The results show that their MAIN, DLE, and IIFA are not significantly correlated to their reading comprehension performance. 
Table 7. Correlations between variables for PBL and Non-PBL

\begin{tabular}{llrrrrr}
\hline Variables & Group & AELA Total & \multicolumn{1}{c}{ MI } & \multicolumn{1}{c}{ DLE } & \multicolumn{1}{c}{ IIFA } & COIC \\
\hline RC & PBL (26) & $.773^{* *}$ & $.647^{* *}$ & $.560^{* *}$ & $.560^{* *}$ & $.532^{* *}$ \\
Post-test & Non-PBL (30) & .064 & .287 & .117 & .216 & $.508^{* *}$ \\
\hline
\end{tabular}

Note. $\mathrm{MI}=$ Motivational Intensity; DLE $=$ Desire to Learn English; IIFA $=$ Interest In Foreign Affairs; COIC $=$ Communication Inside and Outside the Classroom; $\mathrm{PBL}=$ problem-based learning; non-PBL $=$ non-problem-based learning. ${ }^{* *} p<.01$

\subsection{How the Participants in the PBL Group Completed the Problem Solving Tasks}

The fourth research question explored how the participants conducted the task of problem solving. This question was answered by the 26 participants' self-reports on the tasks they conducted throughout the 10 weeks. The self-reports were analyzed by screening out, categorizing the participants' description of tasks, and further calculating the frequency of each task. The percentage score of each task was calculated by the following step: the frequency of each task was added up and further divided by the totaled task frequency. In total, there were eight types of tasks; the totaled frequency was 74. The tasks and percentages of each task are presented in Figure 3.

The task ranked with the highest percentage indicated that there were 23 participants describing that they joined the discussion after class. Among the 26 participants, up to $89 \%$ of the PBL participants extended their learning after class. This result suggests PBL participants' active involvement and attitudes. Schmidt (1993) indicated that discussions may facilitate conception elaboration and knowledge reconstruction. It can be noted that during the discussion, they simultaneously completed other tasks. For example, five of the 23 participants at the same time mentioned that they designed the framework and made a decision about the themes of the oral presentation, and another 11 participants helped to search for data.

The task ranked with the second highest percentage was searching for data. In total, 20 participants expressed that they searched for information on the Internet, in the textbook, and in the hard-copy books. An extract from one participant's self-report is as follows:
After I read the textbook and the questions, I began to search for more online resources and information that could support me to answer the questions. I selected several websites which offered knowledge and information directly related to the questions.

As for the task of writing the draft, seven out of 11 participants described that they read the data that their group members provided and copied down some key points and sentences. For example, one participant cited the sentences in the textbook and the Internet to write the draft; once in a while he wrote some sentences and phrases by himself (see the example in Appendix B). The writing draft demonstrated how the participants applied the knowledge in different resources to solve the problem. In addition, another three participants stated that they copied down a couple of short paragraphs from the Internet data and combined them as a whole report.

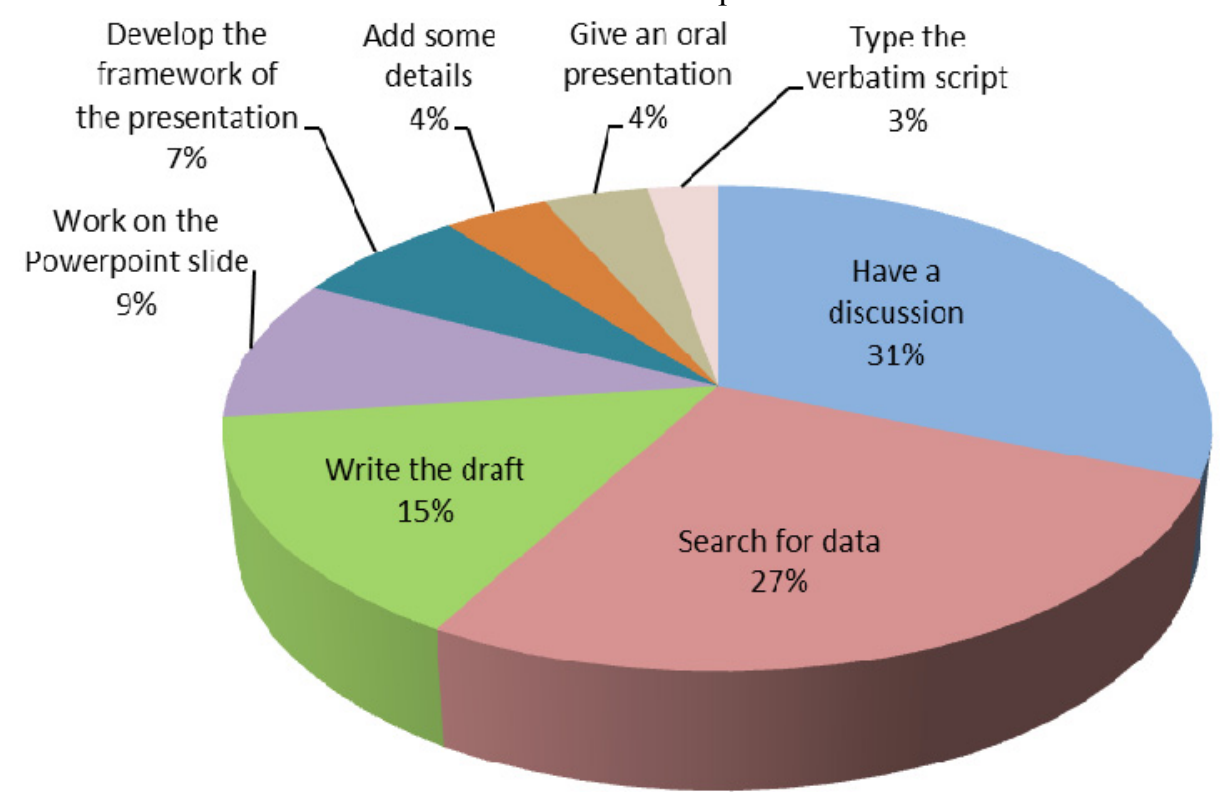

Figure 3. The PBL participants' tasks conducted to identify the solutions to the problems 
Regarding the task of adding the details, three participants stated that they added some details to the PowerPoint slides after reading the final version before the oral presentation. Two of them were the presenters and one was the group leader. This task represented that the abilities to comprehend the data comprehensively, synthesize the data, and undertake critical thinking. For example, two participants respectively added an ending paragraph to the report. The participants' original writings were as follows:

According to the above-mentioned dolphins' facts, we can understand dolphins more than before. The dolphin is a magical animal, and lets people want to get close to it. If you have available time, you will have a good chance to watch dolphins in some professional place, such as Farglory Ocean Park.

I think that dolphins and people have many similarities. Possibly we humans and the dolphins lived together before. This is not impossible, right? Dolphins will soon be on the brink of extinction. We have to protect them and love them in the future.

In general, the participants in the PBL group claimed and undertook different tasks to identify the solutions. The participants probably practiced RC strategies when completing the tasks listed in Figure 3. This is because these tasks were related to reading the data. Moreover, the duration of one unit was 5 weeks. All groups demonstrated their oral presentation in the last meeting and each task was completed as scheduled. Coping with the tasks demonstrated the attitudes among the group members. This probably explains why the PBL group demonstrated a significantly more active English learning attitude than their counterparts.

\section{Conclusions}

In general, the statistical results revealed that PBL participants made much more improvement in reading comprehension, the application of SUBM and SDET strategies, and their active English learning attitude than their counterparts. The results of the self-reports showed that the PBL participants worked in groups and tackled different tasks to identify the potential solutions. As shown in Figure 3, the eight tasks are instinctively allocated in a specific sequence by the members. If one member could not complete his/her task, then the succeeding member could not commence his/hers. Thus, inter-group cooperation was vital to completing all of the tasks within the determined schedule. Their cooperation with each other indicated that they had AELAs.

In the EFL context, it is extremely important to train university students to master English reading skills and to cultivate positive learning attitudes. Armed with the results concluded in the present study, some instructional recommendations for integrating PBL into English classes are presented. First, the class should be divided into small groups. In the present study, the PBL teaching procedure featured small group interaction. The participants were encouraged to interact with each other both inside and outside of the classroom. Through the small group scaffolding, each group can be assigned a task to complete, and hence each student can engage in collaborative learning with other group members. It appears that this small-group model builds up an intimate connection among learners, and consequently supports the learners in extending their English learning outside the classroom. Each learner was bonded together in a group. With the PBL curriculum, English learning could be mediated by different levels of small-group scaffolding. In the EFL context, there is quite a limited English-speaking environment. The PBL group designed with small groups mediated this disadvantage.

Second, the learner should be trained in self-directed learning. In the process of conducting the PBL approach, students are directed to take responsibility for their own learning. The instructor may design the problem-solving task to lead the students learn English actively. In this study, the participants needed to undertake a series of subtasks in and out of class, such as reviewing the assigned materials, reading detailed information, figuring out the answers to the problems, synthesizing the data, and further presenting the solutions. The instructor may design a competition among small groups and offer rewards to the groups who perform most effectively.

Third, the group facilitator/leader plays an essential role, and may exert considerable influence on his/her group members. The group facilitator may act as a role model to foster learning and offer the group members an opportunity for mutual engagement (Wenger, 1998). If the course is to develop English reading skills, the instructor may choose a student with proficient English reading ability as the group facilitator, demonstrating English reading skills that are essential to the reading curriculum. To foster AELAs, the facilitator may, on the other hand, model his/her attitudes toward English learning.

In this study, the PBL curriculum was designed to expose students to a broad range of English reading texts and to prepare them for a capacity that emphasizes ongoing learning and problem solving. The participants in the PBL curriculum made greater improvement in their RC than the participants learning with the teacher-centered curriculum. This suggests that the PBL students were practicing RC strategies that they could bring to bear in accurately understanding the articles. In this study, it was also observed that the PBL group made great progress in their AELAs. 
Particularly, this group of university students' improvement in AELAs mostly relied on their self-strengthened motivation, strong desire to learn English, and communication engagement.

The results of this study can significantly contribute to the field of foreign/second language education by mapping out the features of active learning attitudes required in learning a second/foreign language, and further provides valuable knowledge on the effects of the PBL approach on EFL learners' reading comprehension. Many factors may affect learners'AELAs. Future research can be carried out to further identify other essential factors.

\section{Acknowledgements}

I gratefully acknowledge the financial support of this research by the Ministry of Science Technology (Taiwan, R.O.C.) under Grant NSC 100-2410-H-019-012-MY2.

\section{References}

Albanese, M. (2000). Problem-based learning: Why curricula are likely to show little effect on knowledge and clinical skills. Medical Education, 34, 729-738. https://doi.org/10.1046/j.1365-2923.2000.00753.x

Alexander, J. E., \& Filler, R. C. (1976). Attitudes and reading. Newark, DE: International Reading Association.

Azman, N., \& Shin, L. (2012). Problem-based learning in English for a second language classroom: Students' perspectives. The International Journal of Learning, 18(6), 109-126.

Barrows, H. S. (2000). Problem-based Learning Applied to Medical Education. Southern Illinois University Press, Springfield.

Benson, P. (1997). The philosophy and politics for learner autonomy. In P. Benson, \& P. Voller (Eds), Autonomy and independence in language learning (pp. 18-34). New York: Longman.

Blumberg, P. (2000). Evaluating the evidence that problem-based learners are self-directed learners: A review of the literature. In D. Evensen \& C. E. Hmelo (Eds.), Problem-based learning: A research perspective on learning interactions (pp. 199-226). Mahwan, NJ: Lawrence Erlbaum.

Bosuwon, T., \& Woodrow, L. (2009). Developing a problem-based course based on needs analysis to enhance English reading ability of Tai Undergraduate students. RELC Journal, 40-64.

Boud, D. (1988). Moving towards autonomy. In M. Bloor (Ed.), Learning and cognitive development. University of Greenwich MA Reader.

Boud, D., \& Feletti, G. (Eds.). (1991). The challenge of problem-based learning. New York: St. Martin's Press.

Chan, V., Spratt, M., \& Humphreys, G. (2002). Autonomous language learning: Hong Kong tertiary students' attitudes and behaviors. Evaluation and Research in Education, 16, 1-18.

Chang, Y. H. (2010). Group process and EFL learners' motivation: A study of group dynamics in EFL classrooms. TESOL Quarterly, 44(1), 129-154. https://doi.org/10.5054/tq.2010.213780

De Grave, W. S., Schmidt, H. G., \& Boshuizen, H. P. A. (2001). Effects of problem-based discussion on studying a subsequent text: A randomized trial among first year medical students. Instructional Science, 29, 33-44. https://doi.org/10.1023/A:1026571615672

Dods, R. (1997). An action research study of the effectiveness of problem-based learning in promoting the acquisition and retention of knowledge, Journal for the Education of the Gifted, 20, 423-437. https://doi.org/10.1177/016235329702000406

Dörnyei, Z., \& Murphey, T. (2003). Group Dynamics in the Language Classroom. Cambridge: Cambridge University Press. https://doi.org/10.1017/CBO9780511667138

Doucet, M. D., Purdy, R. A., Kaufman, D. M., \& Langille, D. B. (1998). Comparison of problem-based learning and lecture format in continuing medical education on headache diagnosis and management. Medical Education, 32, 590-596. https://doi.org/10.1046/j.1365-2923.1998.00277.x

Duch, B. J., Groh, S. E., \& Allen, D. E. (2001). Why problem-based learning? A case study of institutional change in undergraduate education. In B. Duch, S. Groh, \& D. Allen (Eds.), The Power of Problem-based Learning (pp. 3-11). Sterling, VA: Stylus.

English, M. C., \& Kitsantas, A. (2013). Supporting student self-regulated learning in problem- and project-based learning, Interdisciplinary Journal of Problem-based Learning, 7(2), 128-150.

https://doi.org/10.7771/1541-5015.1339 
Gijbels, D., Dochy, F., Van den Bossche, P., \& Segers, M. (2005). Effects of problem-based learning: A meta-analysis from the angle of assessment. Review of Educational Research, 75(1), 27-61. https://doi.org/10.3102/00346543075001027

Hmelo, C. E. (1998). Problem-based learning: Effects on the early acquisition of cognitive skill in medicine. Journal of Learning Science, 7, 172-208. https://doi.org/10.1207/s15327809j1s0702_2

Holec, H. (1981). Autonomy and Foreign Language Learning. Oxford: Pergamon.

Kaufman, D. (2004). Constructivist issues in language learning and teaching. Annual Review of Applied Linguistics, 24, 303-319. https://doi.org/10.1017/s0267190504000121

Kivela, J., \& Kivela, R. J. (2005). Student perceptions of an embedded problem-based learning instructional approach in a hospitality undergraduate program. International Journal of Hospitality Management, 24, 437-464. https://doi.org/10.1016/j.ijhm.2004.09.007

Lazarus, B. D., \& Callahan, T. (2000). Attitudes towards reading experienced by elementary school students diagnosed with learning disabilities. Reading Psychology, 21, 271-282. https://doi.org/10.1080/027027100750061921

Lee, L. (2005). Reading and Vocabulary Development 1: Facts and Figures. Boston, Massachusetts, USA: Thomson Heinle.

Lin, L. F. (2011). Problem-based learning approach in multimedia foreign language learning." In Proceedings of Global Learn 2011, edited by S. Barton, J. Hedberg, and K. Suzuki, 1389-92. Waynesville, NC: Association for the Advancement of Computing in Education (AACE).

Lin, L. F. (2016). The Effects of the Task-based Language Teaching and the Presentation-Practice-Production Models on Grammar Instruction. Journal of English Education, 5(1), 45-79.

Lin, L. F. (2017a). English Grammar Instruction and the Problem-based Learning Approach: A Multiliteracies Perspective. The International Journal of Literacies, 24(1), 17-26. https://doi.org/10.18848/2327-0136/CGP/v24i01/17-26

Lin, L. F. (2017b). Integrating the Problem-based Learning Approach into a Web-based English Reading Course. Journal of Educational Computing Research. Advance online publication. doi 10.1177/0735633117705960

Lipson, M. Y., \& Wixson, K. K. (1992). Assessment and instruction of reading disability: An interactive approach. New York: Harper Collins.

Mayer, R. E. (2005). Introduction to multimedia learning. In Mayer (Ed.), The Cambridge Handbook of Multimedia Learning (pp. 1-16). Cambridge University Press. https://doi.org/10.1017/cbo9780511816819.002

Mergendoller, J. R., Maxwell, N. L., \& Bellisimo, Y. (2006). The effectiveness of problem-based instruction: A comparative study of instructional methods and student characteristics. Interdisciplinary Journal of Problem-based Learning, 1(2), 49-69. https://doi.org/10.7771/1541-5015.1026

Merisuo-Storm, T. (2007). Pupils' attitudes towards foreign language learning and the development of literacy skills in bilingual education. Teaching and Teacher Education, 23, 226-235. https://doi.org/10.1016/j.tate.2006.04.024

Neville, D. O., \& Britt, D. W. (2007). A problem-based learning approach to integrating foreign language into Engineering. Foreign Language Annals, 40(2), 226-246. https://doi.org/10.1111/j.1944-9720.2007.tb03199.x

Norman, G. R., \& Schmidt, H. G. (2000). Effectiveness of problem-based learning curricula: theory, practice and paper darts, Medical education, 34, 721-728. https://doi.org/10.1046/j.1365-2923.2000.00749.x

Oxford, R. L. (1990). Language learning strategies: What every teacher should know. Massachusetts: Heinle \& Heinle Publishers.

Pauk, W. (2002). Six-way paragraphs: Intermediate level ( $3^{\text {rd }}$ Ed.). Singapore: McGraw-Hill Education.

Peters, E. E. (2010). Shifting to a student-centered science classroom: An exploration of teacher and student changes in perceptions and practices. Journal of Science Teacher Education, 21(3), 329-349. https://doi.org/10.1007/s10972-009-9178-z

Poikela, E., \& Poikela, S. (2005). PBL in context - Bridging work and education. Finland: Tampere University Press.

Savery, J. R. (2006). Overview of problem-based learning: Definitions and distinctions. Interdisciplinary Journal of Problem-based Learning, 1(1), 9-20. https://doi.org/10.7771/1541-5015.1002

Schmidt, H. G. (1993). Foundations of problem-based learning: Some explanatory notes. Medical Education, 27, 422-432. https://doi.org/10.1111/j.1365-2923.1993.tb00296.x 
Schmidt, H. G., Machiels-Bongaerts, M., Hermans, H., Ten Cate, T. J., Venekamp, R., \& Boshuizen, H. P. A. (1996). The development of diagnostic competence: Comparison of a problem-based, an integrated, and a conventional medical curriculum. Academic Medicine, 71, 658-664. https://doi.org/10.1097/00001888-199606000-00021

Shin, I. S., \& Kim, J. H. (2013). The effect of problem-based learning in nursing education: a meta-analysis. Advance in Health Science Education, 18(5), 1103-1120. https://doi.org/10.1007/s10459-012-9436-2

Smith, M. C. (1990). A longitudinal investigation of reading attitude development from childhood to adulthood. The Journal of Educational Research, 83, 215-219. https://doi.org/10.1080/00220671.1990.10885958

Sungur, S., \& Tekkaya, C. (2006). Effects of problem-based learning and traditional instruction on self-regulated learning. The Journal of Educational Research, 99, 307-317. https://doi.org/10.3200/JOER.99.5.307-320

Torp, L., \& Sage, S. (2002). Problems as possibilities: Problem-based learning for K-16 education. Alexandria Virginia, USA: Association for Supervision and Curriculum Development.

Van Boxtel, C., Van der Linden, J., \& Kanselaar, G. (2000). Collaborative learning tasks and the elaboration of conceptual knowledge. Learning and Instruction, 10, 311-330. https://doi.org/10.1016/S0959-4752(00)00031-1

Waring, R. (Ed.). (2009). Cupid the Dolphin. Boston, Massachusetts: Heinle, Cengage Learning.

Wenger, E. (1998). Communities of practice: Learning, meaning, and identity. Cambridge, UK: Cambridge University Press. https://doi.org/10.1017/CBO9780511803932

Yamashita, J. (2007). The relationship of reading attitudes between L1 and L2: An investigation of adult EFL learners in Japan. TESOL Quarterly, 41(1), 81-105. https://doi.org/10.1002/j.1545-7249.2007.tb00041.x

Yashima, T., Zenuk-Nishide, L., \& Shimizu, K. (2004). The influence of attitudes and affect on willingness to communicate and second language communication. Language Learning, 54(1). https://doi.org/10.1111/j.1467-9922.2004.00250.x

Zimmerman, B. J. (2008). Investigating self-regulation and motivation: Historical background, methodological developments, and future prospects. American Educational Research Journal, 45(1), 166-183. https://doi.org/10.3102/0002831207312909

Zimmerman, B. J. (2013). From cognitive modeling to self-regulation: A social cognitive career path. Educational Psychologist, 48(3), 135-147. https://doi.org/10.1080/00461520.2013.794676 


\section{Appendix A The AELAs Questionnaire}

Please write down a number in each blank (from 1 to 7) to demonstrate your agreement with the statement. The number 7 represents strongly agreed with the statement, and the number 1 , strongly disagreed with the statement.

Motivational Intensity (MI)

1. Compared to my classmates, I think I study English relatively hard.

2. ___ I often think about the words and ideas that I learn about in my English classes.

3. If English were not taught at school, I would study it on my own.

4. I I t think I spend fairly long hours studying English.

5. __ I really try to learn English.

6. ___ After I graduate from college, I will continue to study English and try to improve.

Desire to Lear English (DLE)

7. When I have assignments to do in English, I try to do them immediately.

8. I I I would read English newspapers or magazines outside my English course work.

9. During English classes I'm absorbed in what is taught and concentrate on my studies.

10. I__ I would like the number of English classes at school increased.

11. I I believe absolutely English should be taught at school.

12. I _ I find studying English more interesting than other subjects.

Interests in International Affairs (IIA)

13. I I often read and watch news about foreign countries.

14. I I often talk about situations and events in foreign countries with my family and/or friends.

Communication inside and outside the Class (CIOC)

15. I I volunteered to answer or ask questions in class.

16. I I I answered when I was called upon by the teacher.

17. I _ I participated in classroom activities.

18. ___ I asked teachers questions or talked to them outside the class period.

19. I talked with friends or acquaintances outside school in English.

Time Spent Reading English

How much time did you spend reading English academic and amusement texts every week during the treatment?

\section{Appendix B The Example of the Participant's Writing Draft}

I used different formats to show how the participant integrated the sentences from the textbook and the Internet. The underlined sentences are directly cited from the Internet, the italicized are from the textbook, and the sentences in bold are those written by the participant. I presented the participant's original draft without any grammatical corrections.

Dolphins are mammals. They breathe with lungs and they can only stay up to only 15 minutes under water. When the dolphins stranded on the coast, they would not die promptly. Keeping the dolphins wet is extremely essential; if it doesn't wet enough, it could die. Many researchers agree that dolphins are extremely social creatures and actually depend on this interaction for hunting, mating and defending themselves and their pods. The dolphins can't stay alone. They have to live together. When they live together. Do you know how can they communicate with other dolphins? They use a technique called echolocation. This technique uses the same principles of a radar, and it is used to find food and navigate. Dolphins are always hungry; they can eat 11 pounds of fish every day.

\section{Copyrights}

Copyright for this article is retained by the author(s), with first publication rights granted to the journal.

This is an open-access article distributed under the terms and conditions of the Creative Commons Attribution license which permits unrestricted use, distribution, and reproduction in any medium, provided the original work is properly cited. 